\title{
A FILOSOFIA DO SENSO COMUM DE THOMAS REID
}

\author{
José Aparecido Pereira ${ }^{1}$
}

\begin{abstract}
RESUMO
Fazer uma abordagem na qual sejam discutidos os componentes fundamentais da filosofia do senso comum de Thomas Reid constitui-se como a finalidade primordial desse artigo. Veremos que uma das razões que o levou a fazer dessa forma de conhecimento uma constituinte de sua filosofia foi o fato de Reid acreditar que as nossas concepções e crenças repousam sobre primeiros princípios inatos da mente. Desse modo, as nossas concepções básicas surgem em resposta a signos como o resultado desses princípios das faculdades naturais existentes no homem. Assim, esses signos, às vezes, são sensações, estados mentais dando origem a algumas concepções e, outras vezes, não são estados mentais, mas processos físicos nos órgãos dos sentidos.
\end{abstract}

Palavras-chave: Senso comum. Princípios. Empirismo. Mente. Crença.

\begin{abstract}
Make an approach in which key components are discussed in the philosophy of common sense of Thomas Reid was established as the primary purpose of this article. We will see that one of the reasons that led him to make that kind of knowledge a component of his philosophy was that Reid believe that our ideas and beliefs rest on first principles of innate mind. Thus, our basic conceptions arise in response to signs of these principles as the result of the natural faculties existing in man. Thus, these signs sometimes are sensations, mental states giving rise to some conceptions, and sometimes they are not mental states but physical processes in the sense organs.
\end{abstract}

Keywords: Common Sense. Principles. Empiricism. Mind. Belief.

\section{Introdução}

Fortemente seduzido pelo rigor científico de sua época, Thomas Reid estava convicto da possibilidade de se efetivar um estudo parecido em relação à natureza humana. Desse modo, a sua inquietação se guiava pela crença de que uma investigação sobre a constituição humana poderia ser ${ }^{1}$ É mestre e doutor em Filosofia. É professor do Programa de Pós-Graduação Stricto Senso em Gestão do Conhecimento nas Organizações, da UNicesumar e bolsista produtividade e pesquisador do Instituto Cesumar de Ciência, Tecnologia e Inovação (ICETI). Também é professor da Pontifícia Universidade Católica do Paraná. aparecido.pereira@pucpr.br. 
edificada a partir da base segura da observação e do método do raciocínio experimental, muito utilizado nas ciências naturais. Assim, um esboço bem definido desse projeto já o encontramos em suas Investigações na qual ele procura analisar os componentes envolvidos na percepção, tendo como suporte a nossa constituição, mais especificamente, os nossos cinco sentidos. Assim, os seus trabalhos foram guiados pela crença na possibilidade de se construir um novo sistema de conhecimento, erigido agora sobre um fundamento inteiramente novo. Em vista disso, a concretização desse projeto o levará a fazer um longo itinerário em sua obra, revendo uma gama de conceitos e princípios através dos quais será possível compreender o comportamento humano por meio de um procedimento natural de investigação.

Tal empreendimento, entretanto, exigiu que o pensador escocês problematizasse algumas interpretações tradicionais em torno do conhecimento, porque, a seu ver, essas estariam muito distantes de uma legítima descrição do funcionamento de nossos processos cognitivos. Convicto da necessidade de uma revisão em torno das questões que envolviam a epistemologia de seu tempo, o trabalho de Reid se configura como uma nova maneira de conceber o problema da aquisição e justificação do nosso conhecimento e da formação das nossas crenças epistêmicas. Portanto, é tendo como pano de fundo esse projeto audacioso de Reid que pretendemos discutir os elementos que dão sustentação para a sua filosofia do senso comum. Cumpre dizer que a nossa discussão terá como fundamentação teórica duas importantes obras desse pensador, a saber, as Investigações Sobre a Mente Humana ${ }^{2}$ e os Pode-

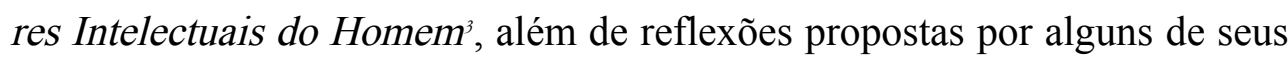
estudiosos.

\section{As razões de Reid em direção ao senso comum}

Historicamente Reid pode ser considerado o fundador da Escola Escocesa denominada a filosofia do senso comum. Nesse sentido, ele é famoso pelo seu forte apelo a essa forma de compreensão da realidade. Mas quais

\footnotetext{
${ }^{2}$ No decorrer do nosso estudo, utilizaremos a abreviatura que os leitores e pesquisadores em Reid assumem correntemente para citar essa obra: IHM. O texto fonte de pesquisa é o editado por Derek R. Brookes, pela Edinburgh University Press, de 2000.

${ }^{3}$ Para essa obra de Reid, utilizaremos a abreviatura que seus leitores e pesquisadores costumeiramente citam: EIP, partindo do texto editado por Derek R. Brookes pela Edinburgh University Press, de 2002.
} 
razões o levaram a fazer dessa forma de conhecimento uma constituinte de sua filosofia? Como sustentou Keith Leher em Thomas Reid-Arguments of the Philosophers, dois motivos podem ser propostos como resposta a essa questão. Em primeiro lugar, pelo fato de Reid acreditar que as nossas concepções e crenças repousam sobre primeiros princípios inatos da mente. Assim, as nossas concepções básicas surgem em resposta a signos como o resultado desses princípios das faculdades naturais existentes no homem. ${ }^{4}$ Esses signos, às vezes, são sensações, estados mentais dando origem a algumas concepções e, outras vezes, eles não são estados mentais, mas processos físicos nos órgãos dos sentidos. Assim, sensações de tato, por exemplo, significam dureza e os processos físicos na retina significam figura. A função única de um signo é dar origem à concepção e crença como resultado das faculdades naturais da mente.

Mas por que concepções e crenças surgem de princípios inatos? Indiretamente todas as nossas concepções e crenças surgem de tais princípios, porque, sem eles, seria impossível a concepção dos objetos do mundo material, sendo que algumas surgem imediatamente, sem a intervenção de um modelo padrão de resposta conceitual. Como concepção e crença são imediatas? Podemos afirmar que isso é um legado de Hume, pois quando ele mostrou ser impossível obter alguma concepção pelo raciocínio de impressão e ideias, por exemplo, a concepção das qualidades externas dos objetos, esses possuindo essas qualidades, do sujeito do pensamento, das causas daquilo que é percebido, infere-se que tais concepções devem surgir de primeiros princípios $^{5}$ que fazem parte da natureza humana. Assim, quando concepções

\footnotetext{
${ }^{4}$ Cf. LEHER, 1989, p. 19.

${ }^{5}$ Em relação, sobretudo, aos primeiros princípios de verdades contingentes, comentadores de Reid têm discutido uma questão muito pertinente: são eles princípios de verdade ou de evidência? De acordo com Leher, os princípios de Reid são, numa primeira instância, mais princípios de verdade do que de evidência. Segundo ele, quando consideramos os primeiros princípios articulados por Reid, encontramos crenças relatando-nos sobre a verdade em vez de evidência. (Cf. LEHER, 1989, p. 197) Por sua vez, Alston parece se posicionar na mesma linha de Leher quando afirma que somente os primeiros princípios, que são distintamente epistemológicos, são aqueles que têm a ver com a confiabilidade de nossas faculdades. Não existem princípios que nos dizem as condições sob as quais um ou outro tipo de crença seja justificada, racional e evidente. (Cf. ALSTON, 1985, p. 435-452) Em contrapartida, James Van Cleve tem uma posição contrária a isso. Ele interpreta que os princípios formulados por Reid são princípios de evidência e não meramente princípios de verdade. Eles são princípios epistêmicos relatando-nos que as deliberações particulares da consciência, memória e percepção e, outras faculdades, são primeiros princípios, isto é, proposições autoevidentes das quais podemos derivar outros itens do conhecimento. (Cf. VAN CLEVE, 1999, p. 20-21)
} 
e crenças são universais e irresistíveis, isso é um sinal de que elas são o resultado de tais princípios. Quando, além disso, é demonstrado que tais concepções e crenças não podem surgir da experiência de impressões e ideias, a suposição nativista é confirmada.

Do que dissemos anteriormente, parece-nos, então, que um dos pontos fundamentais das discussões de Reid em torno do senso comum é a sua suposição de que as percepções ao implicarem concepções e crenças requerem explicações em termos de algum princípio inato da mente, ou seja, devem existir princípios em nossa natureza que dão origem às nossas concepções e crenças na existência dos objetos externos e algumas de suas qualidades quando os percebemos. Eles surgem naturalmente em nós sem instrução prévia e nossas capacidades os aperfeiçoam o tempo todo. Isso nos remete para duas questões importantes: apelar para o inatismo não seria um abandono do empirismo? Se a colocação do inatismo não significa ruptura com o empirismo, como combiná-los ou conciliá-los?

Quanto à primeira questão, acreditamos que a resposta deva ser negativa. Podemos falar da tese de que todos os conceitos são derivados da experiência como empirismo conceitual e da tese segundo a qual todo conhecimento do mundo deriva da experiência como empirismo epistêmico. Reid teria abandonado o empirismo conceitual ao sustentar que existem princípios inatos que dão origem à crença e à concepção? A resposta depende do que se entende por derivado da experiência. Consideremos a tese de Locke segundo a qual a mente é uma tábula rasa onde se escrevem as experiências. Seria a visão de Reid consistente com esse tipo de empirismo? Se Reid estiver certo ao defender que a concepção de uma impressão sensorial é algo além de uma particular impressão, então a experiência requer um princípio de inscrição para escrever qualquer concepção na mente. Desse modo, os primeiros princípios seriam de inscrição, dando origem a concepções acompanhadas por estímulos sensoriais e a presença de sensações ou impressões. Sem tais concepções, embora a mente pudesse receber estímulos, nada conceitual ou representacional seria escrito.

Por conseguinte, a exigência de que estímulos sensoriais deveriam escrever ideias na mente, algo conceitual ou representacional, sem um prin- 
cípio de inscrição é totalmente inútil e vão. Inscrição sem esse princípio não pode produzir algo significável. Portanto, qualquer forma convincente e razoável de empirismo conceitual deve admitir princípios de inscrição e alguns deles devem ser inatos. Isso justifica o porquê de nos posicionarmos negativamente em relação à primeira questão colocada anteriormente. Em outras palavras, acreditamos que Reid ao inserir o inatismo em suas discussões sobre o senso comum, em momento algum estaria rompendo com o empirismo. Tudo nos leva a crer que o contrário seja o mais provável, pois uma análise atenta de suas obras nos mostrará que esses dois elementos se encontram entrelaçados e correlacionados, não podendo ser dissociados ou separados. Aliás, como veremos a seguir, o empirismo constitui-se como o segundo motivo pelo qual ele assumiu e defendeu o senso comum. Sendo assim, entendemos ser muito temerário afirmar que o seu inatismo poderia ter levado a uma dicotomia com a experiência. Por outro lado, o modo como o pensador escocês trata sobre a relação entre princípios inatos da mente e empirismo nos sugere que esses mesmos princípios parecem ser anteriores à experiência e ao próprio empirismo constituindo-se como a condição fundamental para a existência de ambos. Ou seja, sem os princípios inatos da mente seria impossível o empirismo. Nesse sentido, podemos afirmar que ambos se encontram conciliados e combinados. E isso também, em certa medida, responde a segunda questão que colocamos ainda a pouco.

A partir desses elementos, chegamos, então, ao segundo motivo pelo qual Reid faz do senso comum o elemento constitutivo de sua filosofia: o seu empirismo. No seu entender, os defensores da teoria das ideias têm assumido a existência de estados mentais, pensamentos e sensações e tentam provar a existência do mundo externo. Ele parece discordar dessa posição, pois não existe melhor razão para assumir a existência dos estados mentais que assumir a existência das qualidades dos objetos externos. As duas convicções são o resultado das faculdades naturais existentes no ser humano, da consciência, no primeiro caso e, da percepção, no segundo. Ambas são partes da constituição da natureza humana. Assim, se a natureza é enganosa no primeiro caso, ela também pode ser no outro. Como um resultado de reflexão atenta, podemos estudar tanto o mundo externo quanto o mundo interno com cientificidade, mas toda observação pressupõe algum princípio natural 
da constituição humana que produza concepção e crença. Nesse sentido, podemos dizer que Reid adota uma tese simétrica como uma metodologia epistemológica: o conhecimento das operações mentais do mundo interno e o conhecimento dos processos físicos do mundo externo são tratados simetricamente. Ambos devem ser tomados como ponto de partida para a reflexão filosófica. Assim, se for assumida apenas o conhecimento do mundo interno, como fez a teoria das ideias, então, vê-se incapaz de reduzir o mundo material ao mundo mental e, nega-se a existência de tudo. Por outro lado, se for assumido apenas o conhecimento do mundo externo, como o materialismo tende a fazer, então se descobrirá a incapacidade de reduzir o mundo mental ao mundo material e, assim, nega-se a existência do mundo mental completamente. Dessa forma, produz-se tanto um idealista quanto um materialista eliminativos. Nesse sentido, tanto um quanto o outro parece ser absurdo. E o antídoto para o absurdo é a simetria, ou seja, aceitar o senso comum, bem como, o conhecimento do mundo interno e externo como um ponto de partida para a reflexão filosófica.

\section{A Filosofia do senso comum de Thomas Reid}

O que parece claro nos textos de Reid é que a sua doutrina do senso comum tem a pretensão de explicar o conhecimento dos primeiros princípios. ${ }^{7}$ Disso, resulta certa tecnicidade do termo, pois não se trata da sabedo-

\footnotetext{
${ }^{7}$ Reid divide os primeiros princípios do senso comum em dois grupos: verdades necessárias e verdades contingentes. No primeiro grupo, ele alista os seguintes princípios: 1) Princípios gramaticais como, por exemplo, que todo adjetivo em uma oração há de pertencer a um substantivo expresso ou implícito; que toda oração completa deve ter um verbo; 2) Axiomas lógicos, como que qualquer grupo de palavras que não constitua uma proposição não é nem verdadeiro nem falso; que toda proposição é verdadeira ou falsa; que nenhuma proposição pode ser verdadeira e falsa ao mesmo tempo; 3) Axiomas matemáticos; 4) Axiomas em questões estéticas; 5) Primeiros princípios da moral, como, por exemplo, que uma ação injusta tem mais demérito que uma pouco generosa; que uma ação generosa tem mais mérito que uma meramente justa; que nenhum homem deve ser culpado por algo que não estava em seu poder evitar; que não devemos fazer a outro o que consideraríamos injusto que nos fizessem em circunstâncias parecidas; 6) Primeiros princípios metafísicos, como que as qualidades que percebemos por meio de nossos sentidos devem ter um sujeito, que chamamos corpo, e que os pensamentos dos quais somos conscientes devem ter um sujeito, que chamamos mente; que o que começa a existir tem que ter uma causa que o produziu; que podemos inferir com certeza, desígnio e inteligência a causa a partir de sinais ou signos dela no efeito. No segundo grupo, Reid propõe os seguintes princípios: 1) A existência de tudo de que sou consciente; 2) Que os pensamentos dos quais sou consciente são os pensamentos de um ser ao qual denomina "eu", minha mente, minha pessoa; 3) Aquelas coisas que recordo com claridade realmente aconteceram; 4) Nossa própria identidade pessoal e existência continuada; 5) Aquelas coisas que percebemos claramente por meio de nossos sentidos realmente existem, e são o
} 
ria prática ou do tosco bom senso. O nome senso comum pode parecer um tanto quanto que inconveniente, pois apelar para esse tipo de conhecimento no contexto da filosofia, incorre-se no perigo de ser pouco ou não filosófico. Seja como for, o que significa assumir uma postura filosófica em favor do senso comum? Em outras palavras: o que consiste a filosofia do senso comum de Reid? Convém dizer que nem sempre é fácil conciliar os vários elementos que ele diz sobre esse tema. Assim, num primeiro momento, ele o concebe como uma faculdade instintiva da qual somos dotados naturalmente. Mas, em seus escritos mais tardios, frequentemente ele fala do senso comum como sendo um conjunto de proposições epistemicamente básicas. O certo é que, a sua discussão em torno desse assunto é explicitamente confusa, sendo marcada por várias ambiguidades. Diríamos que essa constitui a parte mais confusa do seu pensamento. No entanto, ironicamente, tem sido considerada, também, a parte mais conhecida da sua filosofia. Apesar dessa confusão e ambiguidade, é possível evidenciar alguns pontos que o filósofo estabeleceu para a sua discussão em torno do senso comum. Destacar esses pontos é a nossa intenção a partir daqui

Um aspecto importante, porém obscuro, presente na abordagem reidiana, encontra-se em sua afirmação de que "na linguagem comum, senso sempre implica em julgamento. Um homem de senso é um homem de julgamento. Bom senso é bom julgamento. Insensatez é aquilo que, evidentemente, é oposto ao julgamento correto. Senso comum é o grau de julgamento que é comum a todos os homens com os quais podemos conversar e fazer e negócios ${ }^{8}$ (EIP VI. ii: 424). Essa fala de Reid nos sugere que o senso comum, em si, não é uma noção puramente descritiva, operando somente no nível do raciocínio ou intelecção. Assim, a denominação de racional não que percebemos que são; 6) Temos algum grau de poder sobre nossas ações e a determinação de nossa vontade; 7) As faculdades naturais pelas quais distinguimos a verdade do erro não são falácias; 8) Há vida inteligente em nossos semelhantes; 9) Que certas expressões faciais, sons da voz e gestos do corpo indicam certos pensamentos e disposições da mente; 10) Devemos certo respeito ao testemunho humano em questões de fato, e inclusive à autoridade humana em questões de opinião; 11) Há muitos fatos que dependem da vontade do homem nos quais há uma probabilidade auto evidente, maior ou menor segundo as características; 12) Nos fenômenos da natureza, o que será, provavelmente será igual ao que foi em circunstâncias similares. (Cf. REID, Poderes Intelectuais, 2002, p. 467-512)

8 “ [...] in language common, sense always implies judgment. A man of sense is a man of judgment. Good sense is good judgment. Nonsense is what is evidently contrary to right judgment. Common sense is that degree of judgment which is common to men with whom we can converse and transact business." (EIP VI. ii 424) 
consiste no fato de uma pessoa ser capaz de desenvolver raciocínios sofisticados e bem elaborados. Uma pessoa racional é aquela capaz de gerir seus próprios assuntos, sendo responsável pela sua conduta para com os outros. Portanto, vemos que na explicação de Reid, o senso comum é operativo tanto no nível prático quanto no nível do raciocínio. Ele unifica a distinção entre teoria e prática: "o mesmo grau de compreensão que torna um homem capaz de agir com prudência comum na conduta da vida, torna-o capaz de descobrir o que é verdade e o que é falso em assuntos que são auto evidentes, e que ele distintamente apreende." (EIP VI. ii: 426). Em resumo, "senso no seu sentido mais comum, e, portanto, no seu sentido mais próprio, significa julgamento, embora os filósofos frequentemente o utilizem em outro significado. Disso é natural pensar que senso comum deve significar julgamento comum; e realmente ele significa" ${ }^{10}$ (EIP VI. ii: 424)

Contudo, algumas questões emergem a partir dessa compreensão de Reid em relação ao senso comum: o que se entende por juízo? Faculdades de julgar ou julgamentos atribuídos? E o senso comum, consiste em faculdades de formar crença que todos temos em comum, com um princípio particular? Ou ele consiste de proposições julgadas ou acreditadas, em comum, pelos seres humanos com um princípio particular, sendo algum item naquela totalidade de crenças partilhadas? Essas questões nos permitem ver que as passagens supracitadas deixam transparecer certa ambiguidade. Podemos dizer que, embora Reid quisesse optar por certas proposições aceitas em comum, com sua frase, "princípios do senso comum," ele às vezes, parece escolher certas faculdades que formam crenças compartilhadas em comum. Seja como for, desejar-se-ia que ele tivesse sido mais consistente e mais claro nesses aspectos. Acreditamos que a interpretação segundo a qual Reid, geralmente, entende por "princípios do senso comum”, crenças ou julgamentos compartilhados, isto é, proposições aceitas em comum, deve ser investigada com mais detalhes, visto que, talvez ela se constitua uma chave de

\footnotetext{
9 "The same degree of understanding which makes a man capable of acting with common prudence in the conduct of life, makes him capable of discovering what is true and what is false in matters that are self-evident, and which He distinctly apprehends." (EIP VI. ii: 426)

10 "[...] sense, in its most common, and therefore its most proper meaning, signifies judgment, thought Philosophers often use it in another meaning. From this is natural to think, that common sense should mean common judgment; and so it really does." (EIP VI. ii: 427)
} 
leitura fundamental para que entendamos com mais clareza a sua compreensão sobre o senso comum.

No capítulo II do Ensaio VI dos Poderes Intelectuais do Homem, intitulado "Do Senso Comum" ele nos apresenta a sua definição oficial de senso comum:

Atribuímos à razão duas funções ou níveis. O primeiro é julgar coisas auto evidentes. $\mathrm{O}$ segundo é tirar conclusões que não são auto evidentes daquelas que são. O primeiro é região exclusiva do senso comum e, portanto, ela coincide com a razão em sua [isto é, senso comum] inteira extensão, sendo somente outro nome para um ramo ou grau da razão ${ }^{11}$ (EIP VI. ii: 433).

A passagem talvez seja um pouco excêntrica, visto que Reid, geralmente, entende por razão aquela capacidade segundo a qual discernimos e cremos na necessidade de proposições e na validade de argumentos. Aqui, como podemos observar, ele trata o senso comum como um ramo da razão. No parágrafo seguinte, o motivo para esse uso excêntrico se torna mais claro. Ele pensa que as pessoas comuns não raciocinam ou não refletem muito (não raciocinam muito bem, de qualquer modo). Mas ele não quer chamálas de irracionais ou insensatas. Então, tendo dito que as crenças auto evidentes são uma manifestação da razão, bem como, daquelas inferidas de tal, ele afirma que "é esse grau (de razão) que intitulam as pessoas à denominação de criaturas razoáveis”"12 (EIP VI. ii: 433). Então, é o fato de o homem possuir essa faculdade que ele pode ser visto como um ser racional. Nesse sentido, o senso comum não se contrapõe à razão, ao contrário, ele e a razão constituem a racionalidade humana.

No entanto, a maior dificuldade é compreender ou interpretar o que Reid entende por auto evidente. O contraste demonstrado entre coisas auto evidentes e coisas que não são auto evidentes, mas inferidas daquelas que são, leva-nos a questionar se a distinção que ele tem em mente é aquela entre crenças formadas por inferência e crenças não assim formadas. A resposta é que isso, certamente, é parte do que Reid queria dizer, mas não o todo.

\footnotetext{
11 "We ascribe to reason two offices, or two degrees. The first is to judge of things selfevident; the second to draw conclusions that are not self-evident from that are. The first of these is the province, and the sole province of common sense; and therefore it coincides with reason in its whole extent, and is only another name for one branch or one degree of reason." (EIP VI. ii: 433)

12 It is this degree that entitles them to the denomination of reasonable creatures." (EIP VI. ii: 433)
} 
Coisas auto evidentes são crenças não formadas por inferência, mas nem todas as crenças são auto evidentes. O que deve ser adicionado à crença não formada por inferência para fazê-la auto evidente? Depois de destinar o capítulo III do ensaio VI a outras questões, Reid retorna ao tópico do senso comum no capítulo IV. Ele começa por contrastar crenças formadas por inferência com julgamentos intuitivos (ao invés de julgamentos auto evidentes): "uma das distinções mais importantes de nossos julgamentos é que alguns deles são intuitivos, outros fundamentados sobre argumento" ${ }^{13}$ (EIP VI. iv: 452). Mas imediatamente ele antecipa que essa é uma abordagem diferente ao explicar essa distinção com o conceito de evidência: "o julgamento é levado necessariamente pela evidência, real ou aparente, manifestada para nós todo tempo"14 (EIP VI. iv: 452) Ele então observa que, em alguns casos, a proposição "ter a luz da verdade nela mesma" e que, em outros, ela tem que emprestar sua evidência de outra. As anteriores são, é claro, a auto evidência. Assim, ele propõe a sua definição tradicional de auto evidente: "o julgamento segue a apreensão delas necessariamente; a proposição não é deduzida ou inferida de outra; ela tem a luz da verdade em si mesma, e não tem ocasião para emprestá-la de outra" ${ }^{15}$ (EIP VI. iv: 452) Ele conclui que os conteúdos proposicionais dos julgamentos intuitivos "são chamados primeiros princípios, princípios de senso comum, noções comuns, e verdades auto evidentes" ${ }_{16}$ (EIP VI. iv: 452)

De forma provisória, o que temos, portanto, é o seguinte: princípios de senso comum devem ser encontrados entre aquelas proposições que a), não são aceitas com base na inferência e b), são verdades auto evidentes. Mas isso parece ser complicado, porque Reid considera que proposições contingentes devem ser encontradas entre os princípios do senso comum. É claro que muitas proposições contingentes que acreditamos não se fundamentam na inferência. Talvez não haja problema nisso. A questão é: qual-

\footnotetext{
13 "One of the most important distinctions of our judgments is, that some of them are intuitive, others grounded on argument." (EIP VI. iv: 452)

14 "The judgment is carried along necessarily by the evidence, real or seeming, which appears to us at the time." (EIP VI. iv: 452)

15 “. [... The judgment follows the apprehension of them necessarily [...]; the proposition is not deduced or inferred from another; it has the light of truth in itself, and has no occasion to borrow it from another." (EIP VI. iv: 452)

16 " [...] are called first principles, principles of common sense, common notions, selfevident." (EIP VI. iv: 452)
} 
quer dessas proposições contingentes também satisfaz o conceito tradicional de auto evidente? Assumiu-se, tradicionalmente, que o conceito de uma proposição verdadeira auto evidente, aplica-se somente a verdades necessárias. Tinha Reid uma visão diferente? Consideremos a passagem seguinte, na qual ele desenvolve seu pensamento sobre a questão da evidência:

Isso é demonstrável e foi a muito tempo atrás demonstrado por Aristóteles que cada proposição a qual damos um consentimento racional, deve ter a sua evidência em si mesma ou ser derivada de alguma proposição antecedente. A mesma coisa pode ser dita da proposição antecedente. Como, portanto, não podemos voltar às proposições antecedentes sem um propósito, a evidência tem por último que se apoiar nas proposições, uma ou mais, que tem sua evidência em si mesmas, isto é, sobre primeiros princípios $^{17}$ (EIP VI. viii: 522).

Observemos que nessa passagem, Reid permite somente duas opções: a) proposições aceitas com base na inferência, para a qual nossa aceitação é racional, derivam sua evidencia de alguma proposição antecedente; b) proposições para as quais a nossa aceitação é racional, mas não aceitas na base da inferência, têm sua evidência em si mesma. Mas isso não nos parece realmente correto, pois podemos supor uma terceira alternativa. Imaginemos que, com tudo funcionando corretamente, se forme em alguém a crença de que exista alguma coisa verde diante de si. Essa proposição contingente tem sua evidência em si mesma? Certamente ela não satisfaz o conceito tradicional de verdade auto evidente proposto anteriormente. Então, sua evidência consiste naquilo que o pensador escocês, em outros lugares, chama a evidência do sentido: evidência é a experiência sensorial que alguém está tendo.

Concluímos, então, que os princípios do senso comum se encontram entre aquelas crenças que são sustentadas não por meio da inferência. Certamente esses princípios devem ter um subconjunto de crenças sustentadas e justificadas de modo imediato, sendo compartilhados por todos. Dessa forma, é possível ver na mente de Reid a seguinte linha de pensamento: princípios do senso comum são primeiros princípios compartilhados. São aquelas crenças que temos por certo em nossa vida diária.

\footnotetext{
17 "It is demonstrable, and was long ago demonstrated by ARISTOTELE, that every proposition to which we give a rational assent, must either have its evidence in itself, or derive it from some antecedent proposition. And the same thing may be said of the antecedent proposition. As therefore we cannot go back to antecedent propositions without end, the evidence must at last rest upon propositions, one or more, which have their evidence in themselves, that is, upon first principles." (EIP VI. vii: 522)
} 
"Se há certos princípios, como eu penso que há, que a constituição de nossa natureza nos leva a crer, e que estamos sob a necessidade de ter por certo nas preocupações comuns da vida, sem ser capaz de dar uma razão para elas, esses são o que chamamos os princípios do senso comum; e o que é manifestadamente contrário a eles, é o que chamamos de, absurdo."18 (IHM II. vi: 33)

Essa passagem nos sugere que devemos dar uma olhada em alguns exemplos de princípios do senso comum que o próprio Reid propõe. Vejamos o primeiro, o terceiro e o quinto de uma lista que ele apresenta no Ensaio VI capítulo V dos Poderes Intelectuais do homem - "Os Primeiros Princípios de Verdades Contingentes":

a) Que tudo o que alguém tem consciência existe.

b) Aquelas coisas que recordo com claridade realmente aconteceram.

c) Aquelas coisas que percebemos claramente por meio dos nossos sentidos realmente existem.

Um comentário sobre como entender esses princípios, dar-nos-á a impressão de que eles não são verdades contingentes, mas necessárias: se alguém tem consciência de algo, então é necessário que exista. Ou, se alguém se lembra de alguma coisa, então ela realmente aconteceu. Se alguém percebe alguma coisa, então é necessário que ela realmente tenha existência. $\mathrm{Na}$ linha de raciocínio que estamos considerando no momento, esses princípios, e todos os outros que Reid cita como exemplos de primeiros princípios de verdades contingentes e de primeiros princípios de verdades necessárias, devem ser interpretados como se eles tivessem a seguinte introdução: "todos temos que ter por certo em nossas vidas no cotidiano." Uma compreensão adicional é que a expressão "todos" deve ser entendida como o resumo para: “todos adultos normais". Portanto, o terceiro princípio na lista de Reid poderia ser interpretado como segue: todos nós, que somos adultos normais, temos que ter algo por certo em nossas vidas e aquilo que recordamos claramente, realmente aconteceu.

\footnotetext{
18 "If There are certain principles, as I think there are, which the constitution of our nature leads us to believe, and which we are under a necessity to take for granted in the common concerns of life, without being able to give a reason for them; these are what we call the principles of common sense; a and what is manifestly contrary to them, is what we call absurd." (IHM VI. ii: 33)
} 
A questão crucial que tem norteado a nossa discussão até o momento, tem sido a compreensão de Reid sobre os princípios do senso comum. Os resultados obtidos até aqui é que em seus escritos, encontram-se duas compreensões bem diferentes: a) princípios do senso comum são primeiros princípios compartilhados, e b) princípios de senso comum são o que fazemos e tomamos como certo (ter-por-certo) em nossas vidas no cotidiano. Poderíamos deixar essa discussão nessas duas linhas de pensamento. Contudo, podemos levá-la a um passo adiante com o seguinte questionamento: deve uma dessas linhas ter prioridade sobre a outra? Uma das duas deve ser tomada como determinante? A nosso ver, tudo indica que a última linha de pensamento deve ser assumida como prioridade. O que tomamos por certo em nosso viver cotidiano, inclui coisas que acreditamos não através da inferência, mas que vão muito além. Parece-nos que a visão de Reid era que o filósofo deveria ser guiado por aquilo que tomamos por certo em geral. Se tratarmos a linha de pensamento "ter-por-certo" como determinante, então todos os primeiros princípios compartilhados ficam incluídos entre os princípios do senso comum. Ao passo que, se tomarmos a linha dos primeiros princípios como determinante, então uma grande parte daquilo que é tomado por certo em comum, fica excluída. Cremos que isso constitui um bom motivo para tratar a linha de pensamento "ter-por-certo" como determinante em nossa interpretação daquilo que o pensador escocês estava tentando articular.

\section{Considerações finais}

Embora Reid seja ambíguo e confuso ao refletir sobre o senso comum, a discussão que fizemos nesse artigo nos leva a acreditar que devemos pensar o senso comum como a faculdade que dá origem a um conjunto de crenças ou proposições básicas. Em qualquer caso, ao considerar a sua epistemologia, é conveniente que nos concentremos sobre os aspectos enfatizados por ele em suas obras da maturidade, isto é, o senso comum como um conjunto de crenças básicas ou proposições fundamentais que servem como fundamento para todo pensamento, ação e conhecimento humano. Assim, o seu sistema tem como objetivo dar conta do fato de que os seres humanos 
conhecem certas coisas. Como isso acontece? A resposta é que as noções e crenças se devem à existência de princípios originais, constitutivos da natureza da mente humana (princípios do senso comum), ademais de outros princípios adquiridos por meio da experiência e do costume. Dessa forma, os princípios do senso comum são verdades sem as quais não poderíamos ter acesso a outras verdades. São os primeiros princípios da filosofia, seus fundamentos, a fonte de conhecimento que os sentidos, como tais, não podem dar.

Enfim, em relação ao senso comum de Reid, Keith Leher manifesta uma posição que pela sua importância convém que a citemos aqui ao concluir esse artigo:

o que permanece intocado na filosofia do senso comum é a pressuposição do primeiro primeiro princípio de que nossas faculdades não são falaciosas, porque devemos usá-las para detectar o erro e temos tanto uma grande dependência delas na ciência e no dia-a-dia para detectar erros em nossas crenças quanto para chegar a eles em primeiro lugar. Podemos haver detectado mais erros em nossas crenças inatas que Reid poderia esperar, mas a idéia de que a ciência e a filosofia podem se sustentar sem o suporte dos primeiros princípios da mente humana, os princípios do senso comum, leva, inevitavelmente ao ceticismo. Essa é a lição de Reid. Ele pensava que as bases do empirismo e do senso comum era a correta combinação de psicologia e epistemologia articuladas mais convincentemente no primeiro primeiro princípio. A lacuna da verdade é fechada através daquele princípio dando origem ao conhecimento. Minha conclusão é que o primeiro primeiro princípio combinando psicologia com epistemologia para explicar nosso conhecimento do mundo externo e do interno foi e continua sendo, a melhor explicação de porque nossas faculdades trazem conhecimento do mundo do senso comum e a extensão de tal mundo na ciência. A explicação que Reid oferece de nosso conhecimento do senso comum deve ser distinguida de uma prova de que o cético esteja errado. Devemos nos contentar sabendo que o cético está errado (LEHER, 1998, p. 25).

\section{Referências bibliográficas}

a) Thomas Reid

REID, T. An Inquiry into the Human Mind on the Principles of Common Sense. Ed. Derek R. Brooks, Edinburgh: Edinburgh UP, 2000.

REID, T. Essays on the Intellectual Powers of Man. Ed. Derek R. Brookes. Edinburgh: Edinburgh UP, 2002. 
REID, T. The Philosophical Orations of Thomas Reid. Edited with Introduction and Bibliography by D.D. Todd. Carbondale: Southern Illinois UP, 1989.

b) Sobre Thomas Reid

ALSTON, W. P. "Reid on Perception and Conception". The Philosophy of Thomas Reid. Eds. Melvin Dalgarno and Eric Mattews. Dordrecht: Kluwer Academic Publishers, 1989, pp. 35 - 47.

CHAPPEL, V. "The Theory of Sensations"The Philosophy of Thomas Reid. Eds. Melvin Dalgarno and Eric Mattews. Dordrecht: Kluwer Academic Publishers, 1989, pp. 49-63

ClEVE, J. V. Reid On The Principles of Contingent Truths. In: Reid Studies, Vol. 03, no 01, Autumn 1999, pp.03-23

CLEVE, J. V. "Reid's Theory of Perception". The Cambridge Companion to Reid. Eds. Terence Cuneo and René Van Woudenberg. Cambridge: Cambridge UP, 2004. pp. 101-133

COPENHAVER, R. Thomas Reid's Direct Realism. In: Reid Studies, Vol. 04, nº1, Fall, 2000.

CUNEO, T.; WOUDENBERG, R. V. (Eds). The Cambridge to Thomas Reid. Cambridge: Cambridge University Press, 2004

LEHRER, K. Reid on Consciousness. In: Reid Studies, Vol. 01, nº 01, 1986, pp. 01-09

LEHRER, K. Reid, Hume and Common Sense. In: Reid Studies, Vol. 02, $\mathrm{n}^{\circ}$ 01, Autumn 1998, pp. 15-26.

LEHRER, K. Thomas Reid, The Arguments of the philosophers. London and New York: Routlegde, 1991.

WOLTERSTORFF, N. "Reid on Common Sense". The Cambridge Companion to Reid. Eds. Terence Cuneo and René Van Woudenberg. Cambridge: Cambridge UP, 2004. pp. 77 - 100. 